\title{
Challenges in Materials Research for Sustainable Nuclear Energy
}

\author{
Baldev Raj (Indira Gandhi Centre for Atomic Research, India) \\ M. Vijayalakshmi (Indira Gandhi Centre for Atomic Research, India) \\ P.R. Vasudeva Rao (Indira Gandhi Centre for Atomic Research, India) \\ K.B.S. Rao (Indira Gandhi Centre for Atomic Research, India)
}

\begin{abstract}
Global energy demand is expected to increase steeply, creating an urgent need to evolve a judicious global energy policy, exploiting the potential of all available energy resources, including nuclear energy. With increasing awareness of environmental issues, nuclear energy is expected to play an important role on the energy scenario in the coming decades. The immediate thrust in the science and technology of nuclear materials is to realize a robust reactor technology with associated fuel cycle and ensure the cost competitiveness of nuclear power and to extend the service life of reactors to 100 years. Accordingly, the present-generation materials need to be modified to meet the demands of prolonged exposure to irradiation and extended service life for the reactor. Emerging nuclear systems incorporate features to ensure environmental friendliness, effective waste management, enhanced safety, and proliferation resistance and require development of high-temperature materials and the associated technologies. Fusion, on a longer horizon of about five decades, also requires the development of a new spectrum of materials. The development of next-generation materials technology is expected to occur in short times and is likely to be further accelerated by strong international collaborations.
\end{abstract}

\section{Introduction}

The global energy scenario is dynamic, demanding periodic evaluation. The quantitative estimate of global power demand and share of various resources are available in a number of recent predictions $^{1}$ (see also the Introductory article by Arunachalam and Fleischer in this issue). These predictions indicate that an innovative global energy policy exploiting the potential of all available resources is essential to meet the future demand. Nuclear power is expected to play a key role in meeting the global energy demand in the coming decades.

Nuclear power can be generated using two types of nuclear reactions: fission and fusion. In the fission reaction, the nucleus of a heavy atom such as uranium ${ }^{235} \mathrm{U}$ or ${ }^{233} \mathrm{U}$ ) or plutonium $\left.{ }^{239} \mathrm{Pu}\right)$ is split into lighter fragments, releasing a large amount of energy ( $200 \mathrm{MeV}$ per fission event). In fusion, on the other hand, nuclei of smaller atoms are fused into a larger nucleus, producing energy (for example, isotopes of hydrogen can be fused to produce a helium nucleus, a neutron, and energy: ${ }_{1}^{2} \mathrm{H}+$ ${ }_{1}^{3} \mathrm{H} \rightarrow{ }_{2}^{4} \mathrm{He}+{ }_{0}^{1} \mathrm{n}+17.6 \mathrm{MeV}$ ). Fission-based nuclear technology is well established, whereas fusion technology is expected to become commercially available in the second half of the century.

Currently, there are 443 commercial fission-based nuclear reactors, which account for about $15 \%$ of global electric power generation. The present nuclear energy generation capacity of $370 \mathrm{GWe}$ (gigawatts electrical) is expected to increase to $500 \mathrm{GWe}$ or more by 2030 and $1500 \mathrm{GWe}$ by 2050 . The recent renaissance of nuclear power is due to many factors: environmental awareness related to climatic changes, increased reliability, improved safety culture, and the necessity for sustainable energy.
The growing concern about climatic changes has provided the impetus required for the growth of green energy technologies. In this context, nuclear energy is a meaningful option, as it is a nearly carbon-free source of power, evaluated over the entire lifecycle approach. Nuclear energy production does not involve emission of hazardous gases such as $\mathrm{SO}_{2}$. The reliability of commercial nuclear power plants has substantially improved in the past decade. The world average nuclear power plant availability improved ${ }^{1}$ from $71.0 \%$ in 1990 to $83.2 \%$ in 2004. The nuclear industry has been able to meet the continuously increasing safety standards, using the concept of "defense in depth." This approach provides two advantages: first, to prevent accidents, and second, if prevention fails, to limit their possible consequences. The World Association of Nuclear Operators has reported ${ }^{2}$ a significant reduction in the safety accident rate in the nuclear industry (number of accidents per 200,000 work hours) from 5.2 in 1990 to 1.2 in 2006.

Many reliable estimates ${ }^{3,4}$ of nuclear fuel resources have shown that nuclear power can provide sustainable energy for the future. The identified conventional, recoverable resources ${ }^{5}$ of uranium (4.7 million tonnes of uranium, MtU) would be sufficient ${ }^{3}$ to last for about 70 years, based on the present projection of consumption of uranium (assuming once-through fuel cycle of light water reactors). Additional conventional resources, estimated to be about $10.1 \mathrm{MtU}$, would ensure uranium availability for a longer period of 270 years. This estimate can be further enhanced if unconventional resources such as phosphate deposits or seawater are included. Introduction of the fast reactor fuel cycle with recycling would further significantly improve the fuel availability. In this scenario, identified conventional 
recoverable resources of uranium will ensure fuel availability for 4,800-5,600 years. This estimate increases to $16,000-19,000$ years if total conventional resources of uranium are considered. Thorium is known to be three times as abundant in Earth's crust as uranium, and the technology of a thorium fuel cycle will further enhance the sustainability of nuclear power.

The high heating value of fuel, relatively high energy density, and possibility of high conversion efficiency are some of the additional advantages of nuclear power.

The widespread use and public acceptance of nuclear energy revolve around a few key issues such as safety, management of nuclear waste (see also sidebar by Ewing in this issue), cost competitiveness, and proliferation resistance (see sidebar by Hecker in this issue). Although nuclear waste is highly radioactive, its volume is far less than that of the waste produced in fossil power plants. The ultimate disposal of the nuclear waste in the public domain is still a cause of concern. International research and development (R\&D) efforts are focused on reducing the radiotoxicity and time for storing high-level radioactive waste, and there are indications that robust technologies can be developed for the safe disposal of nuclear waste. ${ }^{6}$ The cost of nuclear energy has to become competitive with other energy resources to ensure its sustained growth. One contribution to the cost is the long time required for constructing a nuclear reactor, which is partly due to the procedures involved in getting clearances from regulatory bodies and satisfying stringent safety demands. Both the political decisions and national policies arising from nuclear proliferation issues and concern regarding the safety of nuclear fuel during handling and transport act as hindrances to the increased utilization of nuclear energy. However, emerging recycling technologies seek to enhance proliferation resistance by ensuring that plutonium is not separated from uranium at any stage. Co-location of fuel-cycle facilities would reduce the requirement that fuel be transported across the public domain and make the fuel more secure. However, the fuel-cycle facilities need to ensure that the high safety standards are strictly enforced, regardless of whether or not the nuclear installations are co-located.

The realization of the importance of nuclear power has enhanced international cooperation in recent years. ${ }^{7,8}$ The International Project on Innovative Nuclear Reactors and Fuel Cycles (INPRO) involving 28 countries and Generation IV with 11 countries are two major international cooperative efforts. These international initiatives consider fast spectrum reactors (breeders or burners) an important option to meet the objectives of next-generation nuclear energy systems. Fast spectrum reactors make use of fast neutrons $(\sim 1 \mathrm{MeV})$ to cause fission of fuel (i.e., uranium or plutonium). Such reactors could be designed to produce more fissile material than they consume, in which case they are called breeders. Burners are fast reactors that produce energy by burning the fuel and/or transmuting minor actinides to short-lived ( $\sim 500$ years) nuclear waste.

Another important option to meet the objectives is closing the fuel cycle. The different stages in a fuel cycle are extraction from the ore, burning in a reactor to produce power, and disposal of used fuel. The burned fuel can be buried directly as a nuclear waste. Alternatively, the reusable or unburned fuel can be separated from the nuclear waste before the waste is buried in deep geological repositories. Closing the fuel cycle refers to the option of recycling the fuel back to the reactor, after the reusable fuel has been recovered from the burned fuel.

Long-term targets include (1) increased thermal efficiency through a shift to high-temperature reactors; (2) multiple industrial use of high-temperature reactors; (3) improved fuels and better coolants; (4) improved safety, reduced nuclear waste, and better proliferation resistance through in situ incineration using accelerator-driven systems (ADS); and (5) development of commercial fusion technology.

The road map for multiple-use reactors with better thermal efficiency involves developing high-temperature reactors (the core outlet temperatures of which can be as high as $1273 \mathrm{~K}$ ) and using fission-generated heat for commercial purposes such as desalination to produce potable water, heating of buildings, or production of hydrogen as fuel. High-temperature reactor technology started in the 1950s and continued until the middle of the 1970s, within the framework of the Organisation for Economic Co-operation and Development and the Nuclear Energy Agency (OECD/NEA) international collaborations. Although this technology lost its economic competitiveness to water reactors, interest has been revived recently. ${ }^{9,10}$ For example, Japan commissioned two test reactors in 1998 and 2000. This technology should be able to achieve commercialization in the first quarter of the 21 st century.

In the case of fast spectrum reactors, different fuels, including metals, oxides, carbides, and nitrides, and coolants such as sodium, $\mathrm{Pb}, \mathrm{Pb}-\mathrm{Bi}$, helium, and carbon dioxide gas are being evaluated. The higher outlet temperature of the coolant ( $~ 873-$ $923 \mathrm{~K}$ ) and better coolants are expected to increase the thermal efficiency. Metallic fuels can generate or breed fuel better than oxides, carbides, and nitrides, and metallic fuels can be developed that can generate 1.5 times more fresh fuel than the amount of fuel burned, thus ensuring a sustained high pace of growth of nuclear power. Current technology is mature for developing commercial sodium-cooled fast reactors using mixed U-Pu oxide fuel, in a time horizon of 15-30 years.

Utilization of thorium, through its conversion to ${ }^{233} \mathrm{U}$, can increase the power potential of nuclear energy by several orders of magnitude. ${ }^{11,12}$ Hence, energy systems that could utilize thorium for energy sustainability well beyond the 21 st century need to be developed and established for commercial exploitation. In the past, the United States and Germany built demonstration plants based on the thorium fuel cycle. India, which has abundant thorium reserves, has sustained interest in the thorium fuel cycle and developed capabilities in thorium-based reactors and fuel-cycle technologies. Moreover, India has launched the development of an advanced heavy water reactor and associated fuel-cycle technologies as an alternate energy option.

In the longer time horizon are ambitious goals such as ADS and fusion technology. Accelerator-driven subcritical systems ${ }^{13}$ promise nuclear energy with improved safety, generation of fissile isotopes such as ${ }^{233} \mathrm{U}$ from ${ }^{232} \mathrm{Th}$, and minimization of nuclear waste by in situ incineration of long-lived actinides and fission products. Subcritical refers to reactor conditions under which the population of neutrons in one generation is less than that in the previous generation. Under such conditions, a fission reaction is sustained using additional neutrons from an external source such as an accelerator. In ADS, a high-energy $(\sim 1 \mathrm{GeV})$ proton beam from an accelerator strikes a heavy target element (liquid lead or tungsten), which yields copious neutrons called spallation neutrons. These neutrons from the spallation target, that is, the neutron source, drive fission reactions in a nuclear reactor. The surplus availability of neutrons offers two advantages: (1) the nuclear reactor can be operated under subcritical conditions, hence offering a better safety level than critical reactors, and (2) the in situ incineration of long-lived components of spent fuel reduces the storage time of the resulting nuclear waste. ADS technology is in the early stage of development, and commercial exploitation is still a distant target.

Fusion power is a promising long-term solution for global energy issues, given its several advantages: abundant, widely distributed resources; environmental acceptability; and proliferation resistance (materials used in a fusion reactor and 
byproducts of fusion are not suitable for the production of nuclear weapons). The fusion reaction can proceed only if the repulsive electrostatic force between nuclei is overcome. This requires high temperatures $\left(\sim 10^{8} \mathrm{~K}\right)$ and high pressures $\left(\sim 10^{9}\right.$ $\mathrm{Pa})$, and under such conditions, the fuel is in the state of plasma (ionized state of matter). In a fusion reactor, tritium $\left({ }_{1}^{3} \mathrm{H}\right)$, the fuel for sustaining the fusion reaction, is produced in a selfsustained fashion, using lithium as a breeding blanket $\left({ }_{3}^{6} \mathrm{Li}+{ }_{0}^{1} \mathrm{n}\right.$ $\left.{ }_{2}^{4} \mathrm{He}+{ }_{1}^{3} \mathrm{H}\right)$. Fusion research started overhalf a century ago. Pioneering experiments in fusion research were carried out by Russian scientists to demonstrate the feasibility of thermonuclear reaction, to sustain the plasma in various types of magnetic fields, and to deal with instability related to magnetohydrodynamics. Many countries, including the United States, England, France, Japan, and Germany, joined this research effortaround 1968. Theimmediate challenges in establishing fusion technology at the commercial level are associated with issues related to achieving sustainable fusion, creating and confining plasma, generating high temperatures, and managing tritium. Fusion materials that withstand high temperatures, irradiation, and magnetic loads - static and transient - and associated technologies such as remote inspection and maintenance are currently being developed.

With these long-term strategies, the nuclear industry is expected to undergo a paradigm shift from being a mere electricity producer to being an indispensable part of global energy policy.

The successful implementation of advanced nuclear systems depends on the development of suitable materials and relevant technologies (Figure 1). An extensive database is available ${ }^{14-16}$ on a host of nuclear materials: nuclear graphite, beryllium, boron, and engineering materials such as zirconium-based alloys (with low neutron absorption cross sections) for water reactors and nucleargrade steels (with high radiation resistance) for sodium-cooled fast reactors. The present level of maturity of nuclear materials

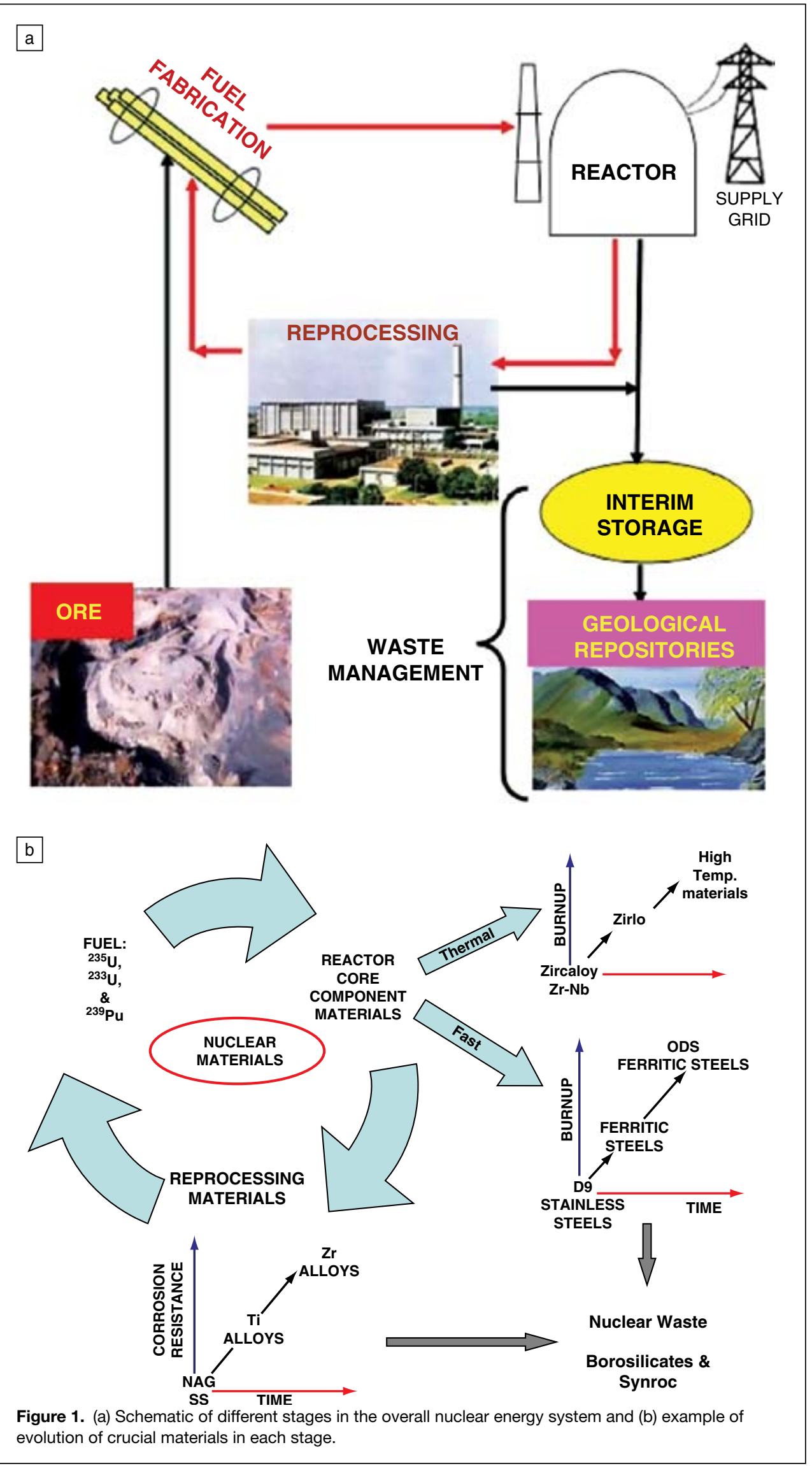


technology involves efforts to achieve high burnup (energy production per unit quantity of the fuel) to reduce the cost of nuclear power, and new domains of materials research are also emerging in response to advanced reactor technologies.

\section{Nuclear Materials: A Brief Preamble}

Nuclear fuel forms the core of any nuclear reactor. The term "nuclear materials" refers to a host of engineering materials that are used in the reactor, other than the fuel, coolant, and moderator. Some examples of nuclear materials are the zirconium-based alloys used in water reactors and the hightemperature radiation-resistant steels used in the sodiumcooled fast reactors. The nuclear materials can broadly be grouped into two categories: core and out-of-core component materials. The core component materials include fuel assemblies and the neighboring coolant channels for water reactors and clad (cylindrical tubes that house the fuel pellets) for the fuel and wrapper (a container that houses fuel elements, in between which the coolant flows) for subassemblies of fast reactors. The out-of-core materials (Figure 2), made of different steels, form the remaining parts of the nuclear steam supply system. General issues of concern about the nuclear materials are radiation resistance, high-temperature mechanical properties, compatibility with the fuel and coolant, and fabricability. The conventional, non-nuclear parts of reactor systems, such as turbines, steam generators, and condensers, called the "balance-of-plant" components, also must function well to improve the performance of the reactor. The turbine and steam generator materials, ferritic steels, should exhibit excellent mechanical properties such as fatigue and impact resistance, in addition to acceptable corrosion and erosion behavior. Some problems related to embrittlement and corrosion have been resolved, and modifications have been incorporated in the design of materials for future reactor systems. Incremental improvements in the properties of materials used in balance-of-plant components are expected, that will result in longer lifetimes for the components, better economy, and enhanced safety. However, the target of long life, beyond 60 years, requires re-evaluation of materials behavior in the newer domain of extended service life.

Newer reactor concepts such as the Small Sealed Transportable Autonomous Reactor, SSTAR, demand the same performance features: compatibility with the coolant and an absence of embrittlement and radiation-induced problems.

Generally, all materials in the reactor core are subjected to demanding conditions of temperature, stress, and neutron irradiation. The service exposure conditions for these materials, including temperature, temperature gradient, irradiation dose, and stresses, depend on the type of the reactor and vary from component to component within the same reactor. This results in materials issues that are specific to the type of reactor and the component, as described in Table I. Generally, in any reactor, the core component materials experience service conditions more severe than the out-of-core materials. Such conditions demand more efforts in the development of core component materials. Intense R\&D efforts since the 1970s in the area of radiation damage; compatibility with fuel, coolant, and fission products; and mechanical properties have led to the development of a wide spectrum of core component materials.

Depending on the energy of the neutrons used for fission of the nuclear fuel, reactors can be broadly classified into two types: thermal and fast reactors. Materials used in thermal reactors (where fission is caused by neutrons with an average energy of $\sim 0.025 \mathrm{eV}$ ) experience relatively less aggressive conditions. The materials used in fast reactors (where fission is caused by fast neutrons with an average energy in the range of $0.2-0.5 \mathrm{MeV}$ ) are exposed to a more hostile environment, such as high neutron fluxes [peak flux of $\sim 8 \times 10^{15}$ neutrons $/\left(\mathrm{cm}^{2} \mathrm{~s}\right)$ compared to $10^{15}$ neutrons $/\left(\mathrm{cm}^{2} \mathrm{~s}\right)$ in thermal reactors] and high temperatures (up to $823 \mathrm{~K}$ compared to $573 \mathrm{~K}$ in thermal reactors). In addition, fuels used in fast reactors are irradiated

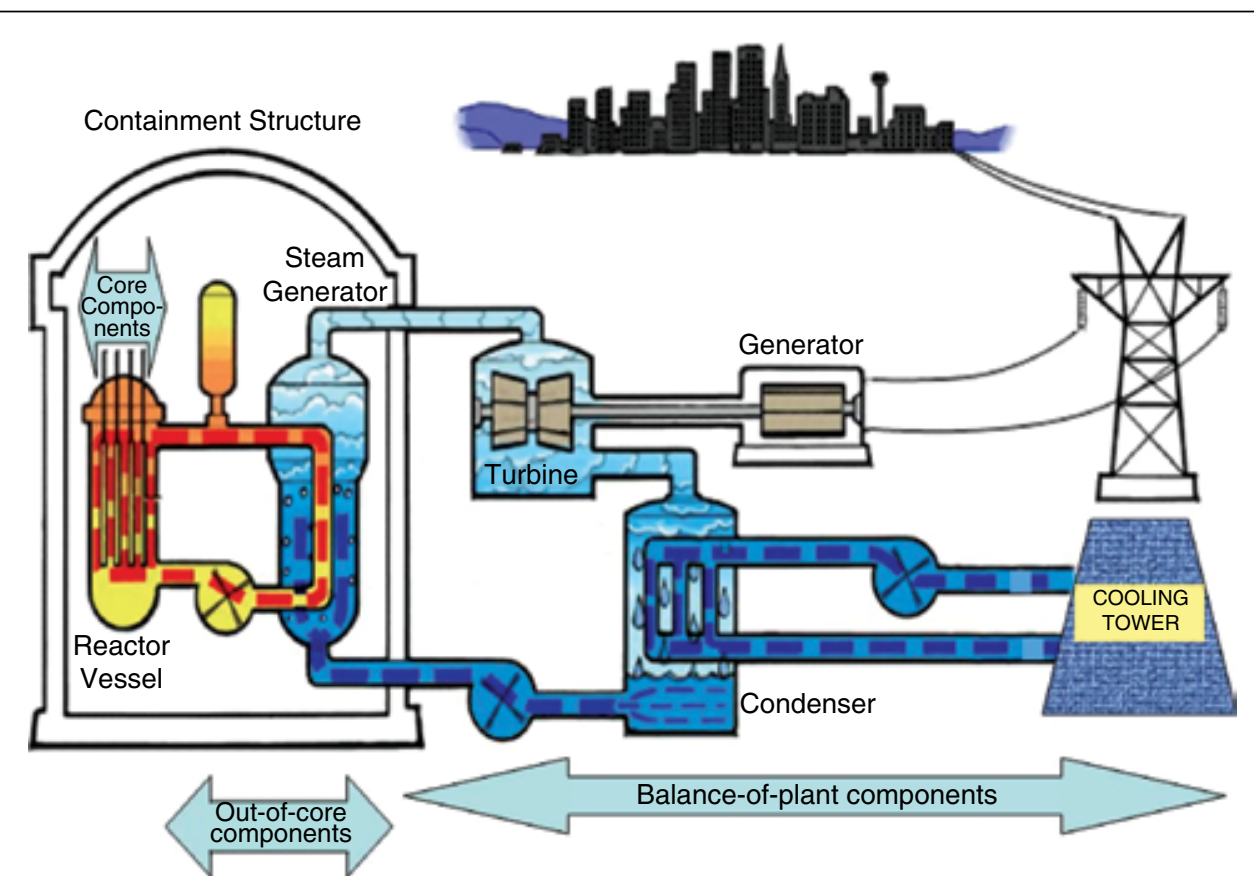

Figure 2. Schematic of different components in a reactor: core components, out-of-core components, and balance-of-plant components. to much higher levels of burnup [target burnup of 200 gigawatt days/tonne $(\mathrm{GWd} / \mathrm{t})$; the present level of burnup is $100 \mathrm{GWd} / \mathrm{t}$ ] than the fuels in thermal reactors (up to $80 \mathrm{GWd} / \mathrm{t}$ ). (Burnup is the energy produced from unit quantity of the fuel. It is expressed in units of $\mathrm{MWd} / \mathrm{t}, \mathrm{GWd} / \mathrm{t}, \mathrm{MWd} /$ tHM, and GWd/tHM, where HM refers to a heavy metal such as uranium and $1 \mathrm{GW}=10^{3} \mathrm{MW}$.)

The main consideration in the choice of materials for a thermal reactor is related to neutron economy, that is, materials should have a low neutron absorption cross section. One material that satisfies this requirement is zirconium, which has a neutron absorption cross section of $2 \times 10^{-24}$ $\mathrm{cm}^{2}$. Hence, significant research has been carried out to develop a wide variety of zirconium-based alloys with chemical properties optimized for improved corrosion and irradiation behavior and with minimal tendency toward hydrogen embrittlement as a result of thermomechanical processing. 


\begin{tabular}{|c|c|c|c|}
\hline Reactor Type & Component & Materials & Major Issues \\
\hline thermal spectrum & cladding & zirconium-based alloys & neutron economy \\
\hline thermal spectrum & pressure vessels, pipings & carbon steels & cost and corrosion \\
\hline thermal spectrum & turbines and steam generators & low alloy steels, $12 \% \mathrm{Cr}$ steels & $\begin{array}{l}\text { cost, corrosion, high temperature } \\
\text { and pressure }\end{array}$ \\
\hline fast spectrum & clad and hexcan & $\begin{array}{l}\text { cold worked } 316 \text { SS } 15 \% \text { Cr- } 15 \% \\
\text { Ni-Ti stabilized stainless steel- } \\
\text { Alloy D9 ferritic steels }\end{array}$ & $\begin{array}{l}\text { void swelling, irradiation creep, } \\
\text { irradiation embrittlement, tensile } \\
\text { strength, ductility \& creep } \\
\text { strength \& ductility, compatibility } \\
\text { with sodium, fuel \& fission } \\
\text { products }\end{array}$ \\
\hline fast spectrum & structural materials & $\begin{array}{l}316 \mathrm{~L} \text { stainless steels or } 316 \mathrm{~L}(\mathrm{~N}) \\
\text { stainless steels }\end{array}$ & $\begin{array}{l}\text { tensile strength, creep low cycle } \\
\text { fatigue properties, creep- } \\
\text { fatigue interactions, weldability, } \\
\text { fabricability }\end{array}$ \\
\hline fast spectrum & steam generator & modified $9 \mathrm{Cr}-1$ Mo ferritic steels & $\begin{array}{l}\text { compatibility with sodium and } \\
\text { steam and corrosion, fretting and } \\
\text { wear related problems }\end{array}$ \\
\hline
\end{tabular}

The satisfactory performance of many thermal reactors has enabled their licensing for a longer service life. Under such circumstances, radiation embrittlement of pressure vessels becomes another important issue to be addressed. Ferritic steels ${ }^{17}$ for reactor pressure vessels should perform well for 60 or even 100 years. Extension of the service life of a reactor vessel requires development of materials surveillance methodologies to establish acceptable procedures for on-line assessment of structural integrity and prediction of the residual life of present-generation reactors. In-service inspection and repair procedures using remote handling methods or robotics are approaches envisaged to meet the demand of longer lifetimes. In this context, improved understanding of damage mechanisms and modeling and validation of materials surveillance procedures would be very useful. The international nuclear community is confident that a lifetime of 60 years for firstgeneration pressurized water reactor systems can be achieved through innovative solutions. The approaches include introduction of a robust materials surveillance program, small-size specimen testing, and advanced nondestructive examination methods for evaluating fracture toughness and microstructural degradation of materials. Thus, modeling-based predictions of long-term behavior and in-service testing and evaluation of nuclear materials and components become crucial in extending service life to 60 years and beyond.

The materials for core components of fast spectrum reactors should have excellent radiation resistance and superior hightemperature mechanical properties. Void swelling, irradiation creep, and embrittlement govern the in-service performance of the core component materials. Another important property, the compatibility of structural materials with the sodium coolant in fast reactors, is well understood and does not pose a major problem. The corrosive nature of sodium depends largely on the concentration of dissolved impurities such as carbon and oxygen. Reliable technology for monitoring and control of impurities in sodium is available. ${ }^{18}$ However, there is a need to address the engineering aspects of design, fabrication, and inspection techniques to minimize the problem of an accidental leak of a large amount of sodium, in order to maintain high safety standards.

\section{Nuclear Reactor Materials: Present Status and Short-Term Strategies}

Zircaloy, an alloy based on zirconium, has been the workhorse of thermal reactors as a core structural material. Various versions of $\mathrm{Zr}$-based alloys such as Zircaloy-2 ( $\mathrm{Zr}-\mathrm{Sn}-\mathrm{Fe}-$ $\mathrm{Cr}-\mathrm{Ni}$ ), Zircaloy-4 (Ni-free to minimize hydrogen adsorption), and $\mathrm{Zr}-\mathrm{Nb}$ alloy and its variants (better long-term oxidation resistance under irradiation) have been developed. ${ }^{19,20}$ The in-service performance of this generation of materials has reached the technological limits. The average burnup of fuel achieved in thermal reactors is around $50 \mathrm{GWd} /$ t. Attempts to maximize the burnup increase the residence time of materials in the core. For example, the exposure time of an in-core material increases from 30,000 to $45,000 \mathrm{~h}$ (from $\sim 42$ to 62.5 months) when the burnup of the fuel is increased from 45 to $70 \mathrm{GWd} / \mathrm{tU} .{ }^{21}$ At higher burnup, materials issues related to hydriding, irradiation growth, and embrittlement become severe, necessitating development of newer and better materials. Hence, in the 1980 s, strategies were adopted ${ }^{22}$ to develop advanced radiation-resistant materials, leading to ternary and quaternary alloys of $\mathrm{Zr}-\mathrm{Nb}$, such as Zirlo (with tin, iron, and nickel), M5 (with oxygen), E110 (similar to M5), and DX-D4 (a variant with a duplex structure). A complex interplay of chemistry, microstructure, out-of-core behavior, and in-reactor performance necessitates detailed evaluation and validation of many zirconium-based alloys before acceptance in the nuclear industry. The M5 alloy has demonstrated radiation resistance to high burnup values $(70 \mathrm{GWd} / \mathrm{MtU})$, as well as superior resistance against corrosion $(20 \mu \mathrm{m}$ corrosion depth at $70 \mathrm{GWd} / \mathrm{MtU})$, hydriding, irradiation creep, and growth $(<0.7 \%)$. The E110 alloy, with nearly the same chemistry as M5, exhibits inferior performance during off-normal conditions. The duplex cladding DX-D4, an alloy with a duplex structure containing both high- and low-temperature phases, exhibits better mechanical properties and corrosion behavior than Zircaloy-4. Industrial experience with this alloy since $1989^{22}$ has indicated that the alloy is radiation resistant up to a burnup of $60 \mathrm{GWd} / \mathrm{tU}$. Attempts are in progress to achieve burnup of $\sim 80 \mathrm{GWd} / \mathrm{tU}$ by about 2015 , with improved fuel and structural materials.

The accumulated experience in fast reactor technology is mainly from sodium-cooled reactors in a few countries such as 
France, Japan, Britain, the United States, Russia, and India. Two types of materials, stainless steels (SS) and nickel-based alloys, were evaluated in the $1970 \mathrm{~s}$ for core applications, based on their excellent hightemperature mechanical properties. However, subsequent efforts have focused mainly on stainless steels, because nickelbased alloys under irradiation exhibit a high tendency toward helium embrittlement. Three generations of steels have been developed: ${ }^{23}$ variants of austenitic stainless steel (SS) such as $316 \mathrm{SS}$ and D9 (Ti-modified $15 \mathrm{Ni}-$ $15 \mathrm{Cr}$ austenitic steels), 912 Cr-based ferritic steels, and the oxide-dispersionstrengthened (ODS) advanced ferritic steels.

Void swelling and irradiation creep are two major materials issues in fast reactors. The propensity of a material for swelling and irradiation creep is measured in terms of its increase in dimensions with increasing irradiation dose or stress (at constant temperature and dose), respectively (Figure 3a,b). Figure 3a shows the percentage change in the diameter of the material with irradiation dose (measured as dpa, displacement per atom) of neutrons, for different types of cold-worked steels. The point of intersection, $\mathrm{X}$, between the two linear portions of the curve represents the threshold dose. Figure $\mathbf{3 b}$ shows the creep behavior of candidate materials such as stainless steel (D9-15\% Ni,15\%Cr with $\mathrm{Ti}$ and 316SS$8 \% \mathrm{Ni}, 18 \% \mathrm{Cr}$ ), ferritic steel (HT9), and nickel-based alloys (D21 and D68). The figure shows the increase in percentage diametrical strain with increasing hoop stress, a mechanical stress causing circumferential forces on rotationally symmetric samples such as a cylinder. These two properties help to rank the candidate materials. For example, D9 is better than 316 stainless steel..$^{27,28}$ Void swelling is

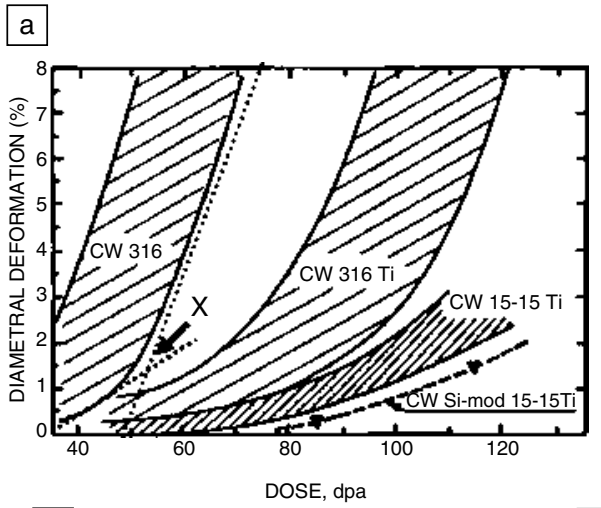

b
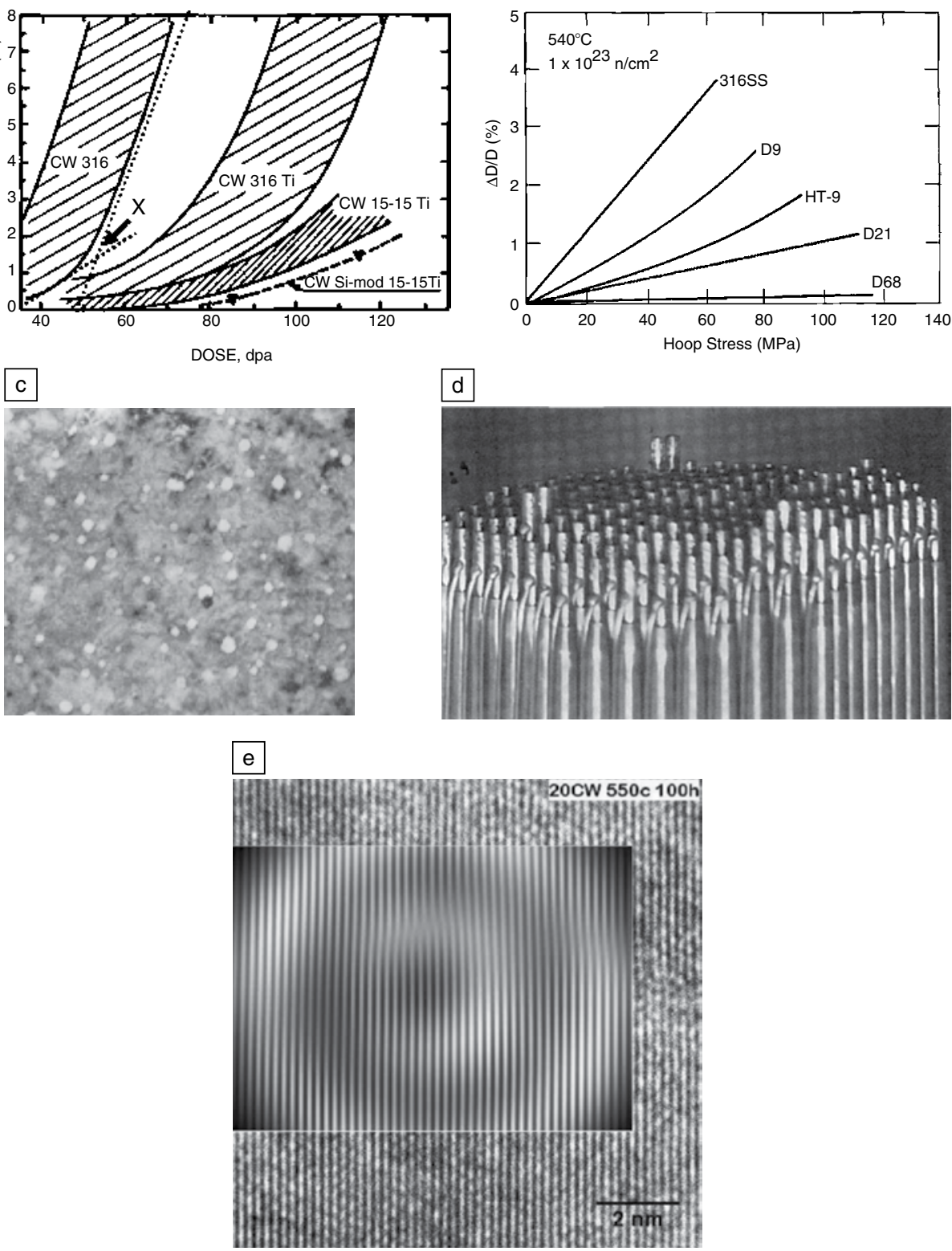

Figure 3. Typical example of development of clad material for fast reactors. Comparison of two crucial parameters for candidate materials for clad: (a) void swelling and (b) irradiation creep. (a) The percentage change in the diameter of the material with irradiation dose (measured as dpa-displacement per atom) of neutrons, for different types of cold-worked steels. The point of intersection, $\mathrm{X}$ between the two linear portions of the curve, represents the threshold dose. (b) The creep behavior of candidate materials like stainless steel (D9 and 316SS), ferritic steel (HT9), and nickel base alloys (D21 and D68). The figure shows the increase in percentage diametrical strain with increase in hoop stress-a mechanical stress causing circumferential forces on rotationally symmetric samples like a cylinder. These two figures help to rank the candidate materials. For example, D9 is better than 316 stainless steel. ${ }^{27,28}$ (c) Electron micrograph $(60,000 \times)$ of voids $(\sim 0.5 \mu \mathrm{m})$ in Type 316 stainless steel irradiated in Dounreay Fast Reactor UK. ${ }^{24}$ (d) Swelling and irradiation creep resulting in dimensional change in the fuel subassembly in the reactor. ${ }^{25}$ (e) High-resolution lattice imaging of TiC in $20 \%$ cold-worked D9, aged at $823 \mathrm{~K}$ for $100 \mathrm{~h} .{ }^{26}$ The inset shows a small region of the image after noise filtering, at the same magnification. These fringes provide information about the lattice strain around the precipitates. The lattice strain is responsible for the superior properties of D9. 
sions and reducing the density of the components. These changes introduce many engineering problems (Figure 3d) and limit the burnup to which the fuel subassemblies can be used safely. The basic approach to develop materials to withstand high fuel burnup has, so far, been to introduce either defects such as dislocations or coherent, stable precipitates (Figure 3e) to delay the onset of swelling, that is, the threshold fluence for the breakaway swelling ( $\mathrm{X}$ in Figure 3a). The same microstructural features improve high-temperature creep behavior as well. Presently, ferritic steels, based on $9 \mathrm{Cr}-1 \mathrm{Mo}$ or $12 \mathrm{Cr}-1 \mathrm{Mo}$ or their variants, are being developed, as these can withstand fluences up to about $180 \mathrm{dpa}$ compared to $\sim 100 \mathrm{dpa}$ for D9 and $45 \mathrm{dpa}$ for 316 stainless steels. In fact, $12 \mathrm{Cr}$ steels can be considered "near-zero-voidswelling" materials. However, the creep properties of currently used ferritic steels are inferior to those of austenitic stainless steels and are within the acceptable limits only up to a temperature of about $823 \mathrm{~K}$. Hence, a combination of D9 for the cladding and ferritic steels for the wrapper is considered the best choice for current-generation sodium-cooled fast reactors. Another major disadvantage of ferritic steels is their tendency to become brittle when exposed to radiation. The ductile-to-brittle transition temperature increases from $223 \mathrm{~K}$ to $\sim 323 \mathrm{~K}$ at the end of its service life. This change in properties increases the possibility of fracture of the wrapper in the reactor during fuel handling and post-irradiation operations. Research is in progress to overcome this problem either by reducing the amount of impurity elements in the steel or by grain boundary engineering.

The short-term developments in fast reactors include an increase in the outlet temperature of the coolant from the present $823 \mathrm{~K}$ to about $1123 \mathrm{~K}$, to enhance the thermal efficiency. Hence, different coolants such as helium gas and lead-based systems including $\mathrm{Pb}$ and $\mathrm{Pb}-\mathrm{Bi}$ are being evaluated. This necessitates the development of radiationresistant ferritic steels with better high-temperature $(>823 \mathrm{~K})$ creep behavior than conventional ferritic steels. Based on three decades of research, ODS ferritic steels are emerging as promising clad materials for use at temperatures higher than $823 \mathrm{~K}$. ODS ferritic steels exhibit superior creep behavior up to a temperature of about $923 \mathrm{~K}$. In this family of steels, ferritic steel with either $9 \mathrm{Cr}$ or $12 \mathrm{Cr}$ is chosen as the matrix, with dispersion of a few fine particles (nanometer scale) of titania and yttria (oxides of titanium and yttrium, respectively). Problems with this class of steels are their fabricability, deformation texture, and anisotropy in mechanical properties. Further research is in progress to establish correlations among chemistry, fabrication process, texture, microstructure, property anisotropy, radiation resistance, and in-reactor performance. Powder metallurgy routes have been identified for the fabrication of ODS alloys into engineering components such as fuel clad. However, for widespread commercial use of ODS alloys, it is essential to demonstrate materials system engineering: dimensional accuracy during fabrication of clad, joining with the end plug, materials evaluation by nondestructive techniques, generation of an engineering database, validation of performance, and codification.

\section{Materials for the Fuel Cycle: Present Status and Short-Term Strategies}

The nuclear fuel cycle is vital for the growth of nuclear technology. The two fuel-cycle options are (a) a closed fuel cycle, in which spent fuel is reprocessed and the fissile and fertile elements recovered for reusing in reactors and (b) an open, once-through cycle, in which spent fuel is treated as waste and disposed in deep geological repositories (see Figure 4). The closed fuel cycle has the advantage of supplying recycled fuel for future reactors. This option assumes importance in the context of the sustainability of nuclear energy. The safety and capacity factors of fuel-cycle plants determine the success of the closed fuel cycle and also contribute to public acceptance of nuclear energy. Arguably, burning of plutonium in fast reactors to produce energy and use of innovative closed fuel recycle technology are the preferred options for enhancing proliferation resistance. This approach would also offer improved waste management by significantly reducing the time required for nuclear waste to attain the natural radioactivity level. On the other hand, the open fuel cycle does not require complex technologies for recycling the spent fuel. The cost of fuel-cycle operations contributes $10-25 \%$ of the unit energy cost of nuclear power generation, depending on the type of separation process, the fuel cycle, and the technological maturity. A robust, safe, and economical nuclear fuel cycle is essential for the growth of nuclear power and its sustainability. ${ }^{29}$

Materials used in the back-end operations encounter aggressive radioactive and corrosive environments. The engineering materials used for various components in conventional aqueous reprocessing technology (plutonium and uranium recovery by extractionPUREX - process) are exposed to corrosive environments such as boiling nitric acid. In waste management, it is necessary to develop matrixes for immobilizing the nuclear waste. These matrixes should remain stable until the radioactivity of the waste reaches the natural activity level (from $\sim 500$ to $1,000,000$ years depending on the radioactive isotopes present in the waste).

Corrosion is the life-limiting factor for structural materials in reprocessing and waste management plants. Type 304L stainless steel has been the conventional choice for containers and piping materials in reprocessing plants, because of its good corrosion resistance in nitric acid media. However, over a period of time, failures of components made from this alloy have been experienced, which led to the development of nitric acid grade (NAG) stainless steels in the 1980s. NAG stainless steels exhibit lower corrosion rates than Type 304L stainless steel, for application in reprocessing plants, and have been used mainly for reprocessing of spent fuel from thermal reactors. However, when a more aggressive medium such as boiling and highly concentrated nitric acid is encountered, titanium- and zirconium-based alloys are favored..$^{30}$ The lifetimes of reprocessing plants (currently 20-30 years) need to be enhanced to match those of reactors (target of $\sim 100$ years). Hence, development of materials for enhancing the lifetimes of the equipment in reprocessing plants will continue to be an important area of research.

Nuclear waste management focuses on the immobilization of radioactive constituents and their long-term isolation of these from the environment. Generally, nuclear waste with a high level of radioactivity is vitrified in a suitable matrix and disposed in a geological repository after the radioactivity level of the vitrified waste has decreased during storage in an intermediate facility.

The characteristics of nuclear waste determine the type of waste form, the key factor in the immobilization process. Three important parameters guide the selection of a matrix for immobilization: chemical durability (ability to lock up the waste in the matrix), chemical flexibility (ability to accommodate variations in the chemistry and physical forms of the waste), and waste loading efficiency (number of disposable canisters required). Glass, generally borosilicate glass, is the current choice as the matrix for immobilizing radioactive waste. Extensive research is being carried out into the development of several other ceramic matrixes that could hold a higher proportion of fission products or actinides and remain stable for thousands of years. ${ }^{31}$ Two new classes of waste form are being developed: glass ceramics and 

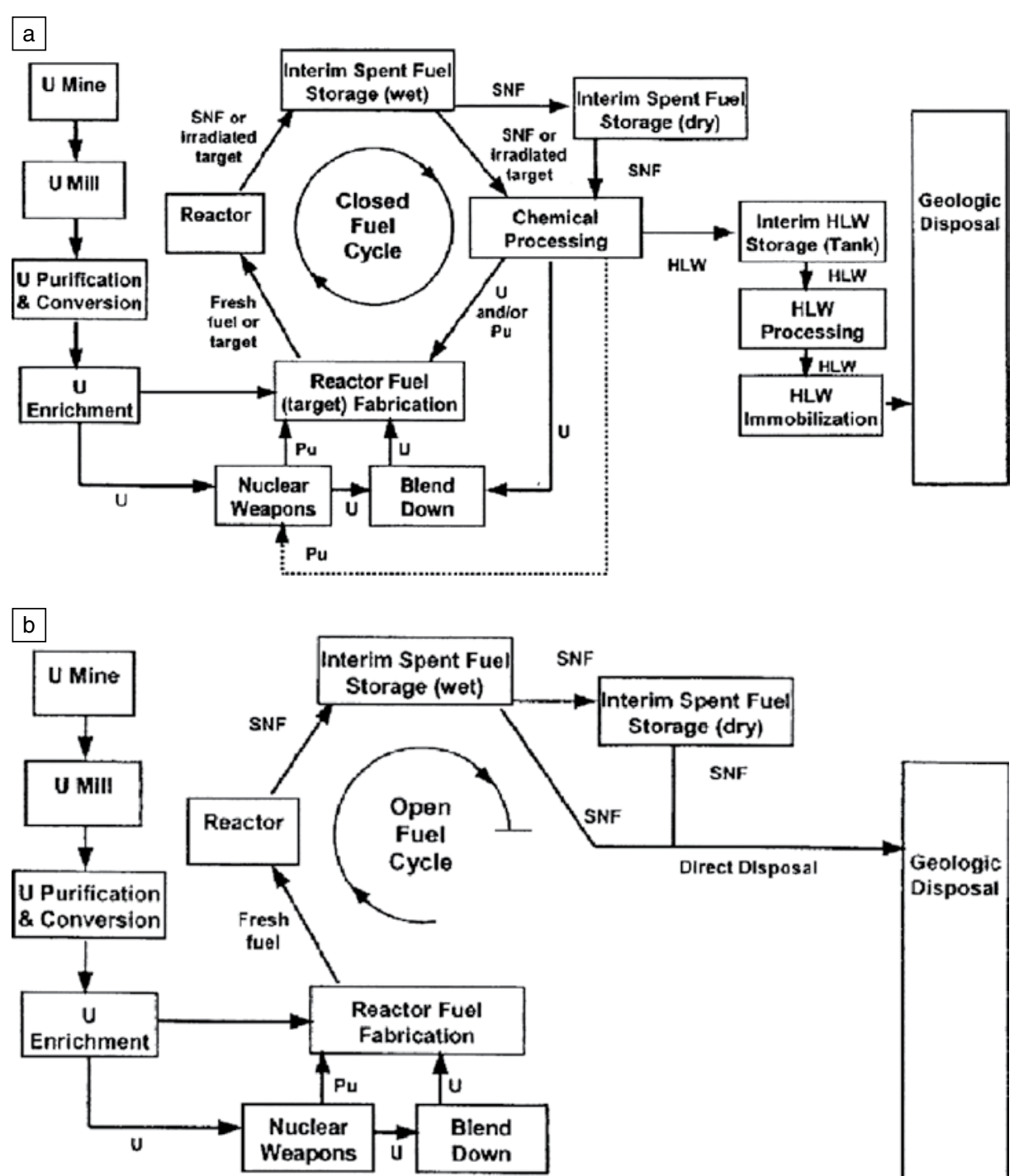

Figure 4. Schematics of (a) closed and (b) open nuclear fuel cycles. Source: Reprinted with permission from End Points for Spent Nuclear Fuel and High-Level Radioactive Waste in Russia and the United States (2003) by the National Academy of Sciences courtesy of the National Academies Press, Washington, DC.

chosen with adequate precaution to ensure its long failure-free lifetime during casting of the vitrified waste product, interim storage, and permanent disposal in a geological repository.

\section{Materials Technology: Long-Term Strategies High-Temperature, \\ Multipurpose Reactors}

High-temperature reactor technology needs a range of new materials: refractory alloys based on $\mathrm{Nb}$, Ta, Mo, W, and $\mathrm{Re}$; ceramics and composites such as $\mathrm{SiC}-\mathrm{SiC}_{\mathrm{f}}$; carbon-carbon composites; and advanced coatings. Materials behaviors such as microstructural stability; mechanical properties such as creep, fatigue, and toughness; and chemical properties such as corrosion and compatibility need to be understood in the newer domains of higher temperatures and higher irradiation levels. Additionally, it is important to establish suitable fabrication and joining technologies, inspection methods for structural imperfections, on-line monitoring methods, and remote repair procedures. Extensive material qualification and technology development efforts are required in these newer systems to establish their suitability for high-temperature reactors.

\section{Fast Reactor Technology}

In the case of fast reactors, long-term objectives include alternate fuels such as carbides or nitrides or metallic alloys and coolants such as $\mathrm{CO}_{2}$ gas or $\mathrm{Pb}$ based liquids. The clad and structural materials for reactors with advanced fuels as the driver

multiphase ceramics. The glass ceramics are suitable for nuclear wastes that are chemically heterogeneous and not compatible with borosilicates. An advanced multiphase ceramic material that is under development, called Synroc, is a titanate-based ceramic consisting of zirconalite (calcium zirconium titanate), hollandite (barium aluminum titanate), calcium titanate, and titanium oxides. The natural minerals in Synroc have several advantages: durability over geological time frames; no undesirable phase-separation reactions; higher solubility of the waste forms than glass; and stable physical properties such as melting temperature, viscosity, and electrical resistance. Further innovations in materials research and maturity of technology in the area of ceramic matrixes are essential for more efficient waste immobilization.

Considering the harsh service environment involved in the vitrification process, Ni-based alloys are commonly used as melter pot materials. Candidate materials for high-level waste canisters and overpacks are generally metals such as copper, iron, stainless steels, titanium alloys, and nickel-based alloys. The container material is fuel are expected to be similar to the types of steels used in oxide-fueled fast reactors. However, advanced materials are required for the reprocessing of the nuclear waste with metallic fuel.

Metallic fuels are best reprocessed by pyrochemical processes using a high-temperature electrochemical route. ${ }^{32}$ These processes use aggressive environments such as highly corrosive molten halide salts. Hence, there is a need for development of a whole new range of materials: corrosion-resistant coatings, graphite crucibles coated with ceramic oxides such as zirconia or alumina, and refractory container materials. These technologies are mature and need only steps for harnessing their potential at the commercial scale. The disposal of nuclear waste generated by pyrochemical reprocessing necessitates development of newer matrixes. A possible solution with respect to the hull waste (pieces of clad material left behind after fuel is processed) is alloying with stainless steel containing $15 \% \mathrm{Zr}$ and conversion to a metal waste form. ${ }^{33}$ Similarly, suitable matrixes 
need to be developed for immobilization of other wastes such as salts used in pyrochemical processes.

\section{Thorium Fuel Cycle}

The thorium fuel cycle does not introduce new issues in reactor materials. However, reprocessing of thorium-based fuels involves the use of fluoride at relatively high concentrations. Hence, extensive R\&D efforts are essential to develop advanced materials resistant to corrosion in fluoride media. Second, fabrication procedures for fuels containing ${ }^{233} U$ have to take into account the presence of the isotope ${ }^{232} \mathrm{U}$, which decays ultimately to thallium, ${ }^{208} \mathrm{Tl}$, which emits hard gamma rays. This necessitates remote fuel fabrication, leading to associated engineering challenges. It can thus be anticipated that remote handling of fuel fabrication processes and the development of advanced materials for recycling will be the key issues in the thorium fuel cycle. Commercial viability of the thorium fuel cycle based on innovations in reactor technology is expected by the middle of 21 st century.

\section{Accelerator-Driven Systems}

The immediate objective in accelerator-driven systems, also called hybrid reactor systems, is to achieve commercial viability of the advanced concept with existing materials. The long-term materials issue is related to the selection of the window material (which separates the reactor from the accelerator) and the structural materials for the reactor. The window material must be resistant to irradiation, corrosion, and embrittlement (liquid metal and helium) and have good thermophysical properties. Presently, different variants of modified ferritic-martensitic steel (T91) and 316L stainless steel are being explored as window and structural engineering materials. ${ }^{34}$

\section{Fusion Technology}

A schematic of a fusion reactor is shown in Figure 5a. Earlier attempts (Figure 5b) such as the Joint European Torus facility and the Princeton Tokamak Fusion Test Reactor have provided the required confidence to launch a major international fusion program, the International Thermonuclear Experimental Reactor (ITER). The scope of the ITER project includes feasibility studies on the production of fusion energy and examination of various concepts using test blanket modules for tritium breeding. ITER is a joint project of the European Community, Japan, Russia, the United States, Korea, China, and India. ITER offers a unique opportunity to test blanket mock-ups of the participating countries in a fusion environment. The success of ITER would be a stepping stone for the future-generation fusion power reactors, such as DEMO, a demonstration reactor, that can be used for validation of inreactor performance of materials and components.

The research efforts in fusion materials can be categorized as those pertaining to plasma facing materials such as the first wall, the divertor, or the breeding blankets and other structural materials. The service conditions, materials issues, and candidate materials for both categories are summarized in Table II. The materials issues in fusion reactors are prominent in the components of the first wall, divertor, limiters, and blankets. These components are subjected to high neutron irradiation, in addition to strong mechanical, thermal, and electromagnetic loadings, both static and transient. The typical operating conditions of the first wall in ITER are generally found to be more severe than those in a fission-based reactor. ${ }^{36}$ The structural materials also should have the least activation from the consideration of nuclear waste disposal and decommissioning at the end of service.

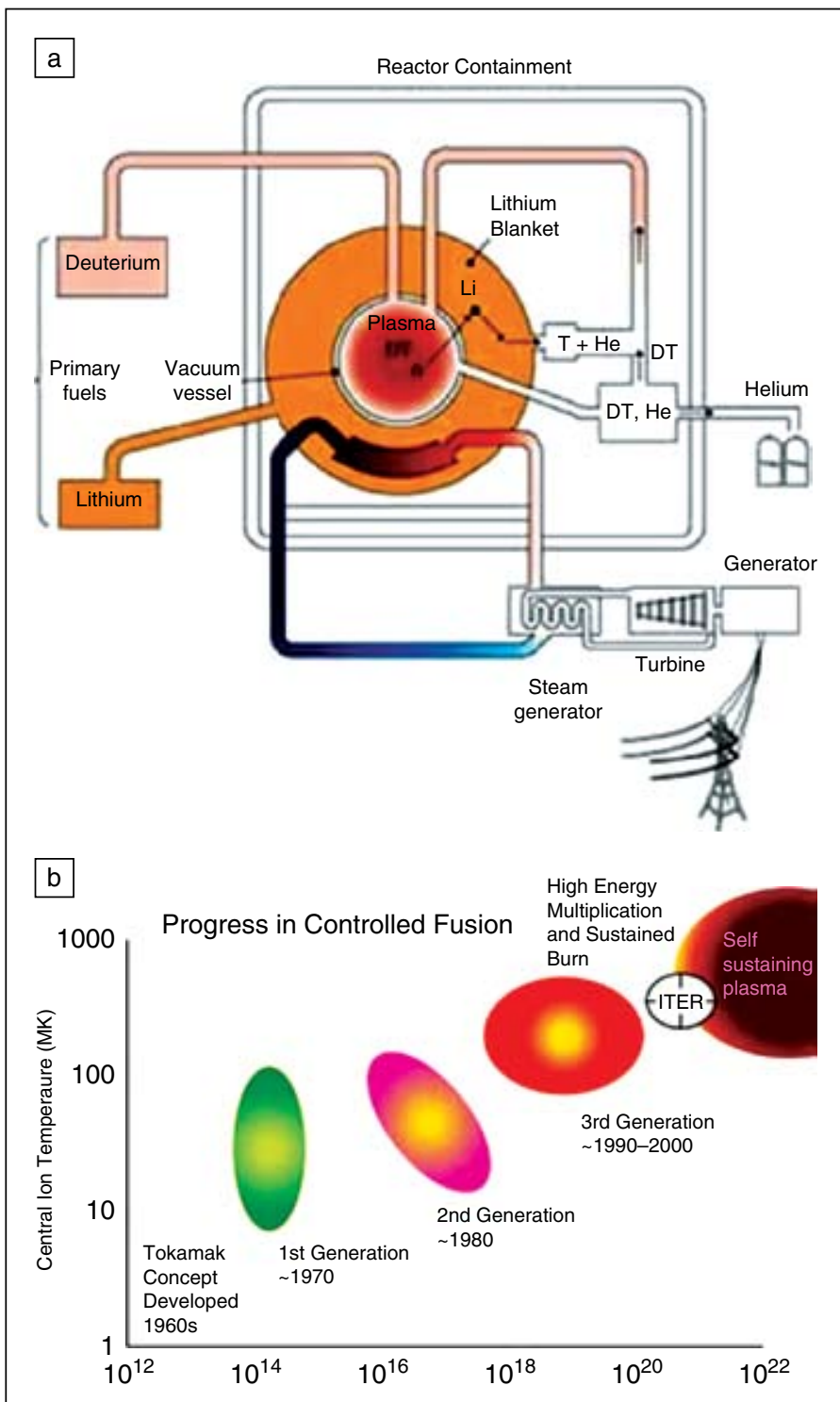

Fusion Triple Product - density (particles/ $\left.\mathrm{M}^{2}\right)$ x confinement time (s) $x$ Temperature (keV)

Figure 5. (a) Schematic ${ }^{35}$ of the ITER fusion reactor. (b) Evolution ${ }^{35}$ of fusion reactor technology: Gradual improvement in the two crucial parameters of the performance of the fusion reactor, namely, fusion triple product (density $\times$ confinement time $\times$ temperature) as the $x$ axis and central ion temperature as the $y$ axis.

These requirements have led to the development of reducedactivation ferritic steels, vanadium alloys, and fiber-reinforced $\mathrm{SiC}$ composite ceramic materials. ${ }^{36}$ The plasma facing materials are essentially tungsten-based refractory alloys. To remove the high heat fluxes from the divertor, heat-sink materials with high thermal conductivities are being developed. In ITER, materials such as $\mathrm{CuCrZr}$ or fiber-reinforced metal matrix composites such as $\mathrm{SiC}$ in a $\mathrm{Cu}$ matrix are being evaluated. Metalmatrix composites also have the advantage of excellent creep resistance at high temperatures in addition to high thermal conductivity. Other plasma facing materials that are being evaluated are carbon-fiber-reinforced carbon, Be-, and W-based materials. The steels and vanadium-based alloys undergo severe hydrogen embrittlement as a result of their exposure to high concentrations of isotopes of hydrogen. Hence, coating tech- 


\begin{tabular}{|c|c|c|c|}
\hline Components & Exposure Conditions & Materials Issues & Candidate Materials \\
\hline $\begin{array}{l}\text { plasma facing } \\
\quad \text { components: } \\
\text { a. first wall } \\
\text { b. divertor } \\
\text { c. breeding blanket }\end{array}$ & $\begin{array}{l}14 \text { MeV neutrons, with } \\
\text { high damage rate } \\
\text { (20-30 dpa/year for } \\
3-4 \text { GW reactor); } \\
10 \text { times higher helium } \\
\text { production (10-15 } \\
\text { appm/dpa) than fission; } \\
\text { Four times more hydrogen } \\
\text { (40-50appm/dpa) than } \\
\text { fission; } \\
\text { High heat flux (0.1- } \\
\text { 20MW/m²); } \\
\text { High temperatures (775- } \\
\text { 3475K) }\end{array}$ & $\begin{array}{l}\text { radiation damage; } \\
\text { high temperature } \\
\text { performance; } \\
\text { sputtering erosion, } \\
\text { blistering, } \\
\text { exfoliation, } \\
\text { hydrogen trapping } \\
\text { and deterioration in } \\
\text { properties; } \\
\text { thermal shock resistance; } \\
\text { thermal conductivity }\end{array}$ & $\begin{array}{l}\text { first wall: } \\
\text { Refractory alloys based on tungsten, or tungsten coated } \\
\text { ODS steel or flowing liquid metal like lithium, gallium } \\
\text { or tin } \\
\text { divertor: } \\
\text { tungsten based alloys; tungsten coated } \mathrm{SiC} / \mathrm{SiC}_{\mathrm{f}} \text { or flowing } \\
\quad \text { liquid metals of lithium, gallium or tin } \\
\text { breeding blanket: } \\
\text { Tritium breeder: } \\
\text { solid: } \mathrm{Li}_{4} \mathrm{SiO}_{4}, \mathrm{Li}_{2} \mathrm{TiO}_{3} \text {, } \\
\text { liquid: } \mathrm{Pb}_{\mathrm{Li}} \mathrm{Li} \\
\text { neutron multiplier: } \\
\mathrm{Be}_{\mathrm{B}} \mathrm{Be}_{12} \mathrm{Ti}^{-}\end{array}$ \\
\hline structural materials & $\begin{array}{l}\text { high temperatures; } \\
\text { radiation damage; } \\
\text { mechanical \& thermo- } \\
\text { mechanical stress }\end{array}$ & $\begin{array}{l}\text { radiation embrittlement, } \\
\text { deterioration in } \\
\text { mechanical properties } \\
\text { under stress and } \\
\text { radiation (similar to } \\
\text { fission reactors) }\end{array}$ & $\begin{array}{l}\text { By 2010: } \\
\text { low activation ferritic-martensitic steels, } \\
\text { By 2015: } \\
\text { ODS ferritic steels, vanadium alloys, } \mathrm{SiC} / \mathrm{SiC}_{f}\end{array}$ \\
\hline
\end{tabular}

nology is being developed to deposit hydrogen permeation barrier coatings between the plasma facing material and the heat-sink material.

The development of structural materials, essentially lowactivation ferritic steels, has proceeded with approaches similar to the ferritic-martensitic steels for fast spectrum reactor technology. Mo and $\mathrm{Nb}$, which cause the strongest activation, are replaced by $\mathrm{W}$, which behaves metallurgically in the same way as Mo. Fusion-specific grades of low activation steels called Eurofer97 and F82H (ferritic steels with iron, chromium, tungsten, vanadium, tantalum, and carbon) are being developed.

Past experience has shown that material behavior is sensitive to the exposure conditions. Extrapolation of the behavior of materials in one fission reactor system to another is very often found to be inaccurate. However, in the absence of a suitable fusion reactor available for the evaluation of fusion materials, simulation experiments using accelerators coupled with modeling studies appear to be a short-term solution. A materials test reactor for the fusion environment is essential for enabling reliable and robust materials development. Fusion researchers and technocrats are aware of this essential requirement and are planning to harness international collaborations to address this challenge.

\section{Challenges in the Science and Technology of Nuclear Materials}

Figure 6 illustrates the evolution of nuclear materials in resonance with changing demands of the nuclear technologies. Generally, the level of expertise developed for different engineering materials for nuclear industry varies widely. The materials for water reactors and sodium-cooled fast reactors have reached a commercial level of maturity, so that only incremental changes are required to meet enhanced perfor- mance targets. However, considerable breakthroughs and innovative approaches are required for materials for reprocessing and waste management plants, especially in a scenario where advanced fuels are applied. Similarly, the materials technology for high-temperature reactors, accelerator-driven systems, and fusion reactors requires more attention in the future. Sophisticated experimental techniques, modeling approaches, and methodologies for translating laboratory results into codes for commercial-scale deployment need to be developed. The question of the reliability of the extension of properties evalu-

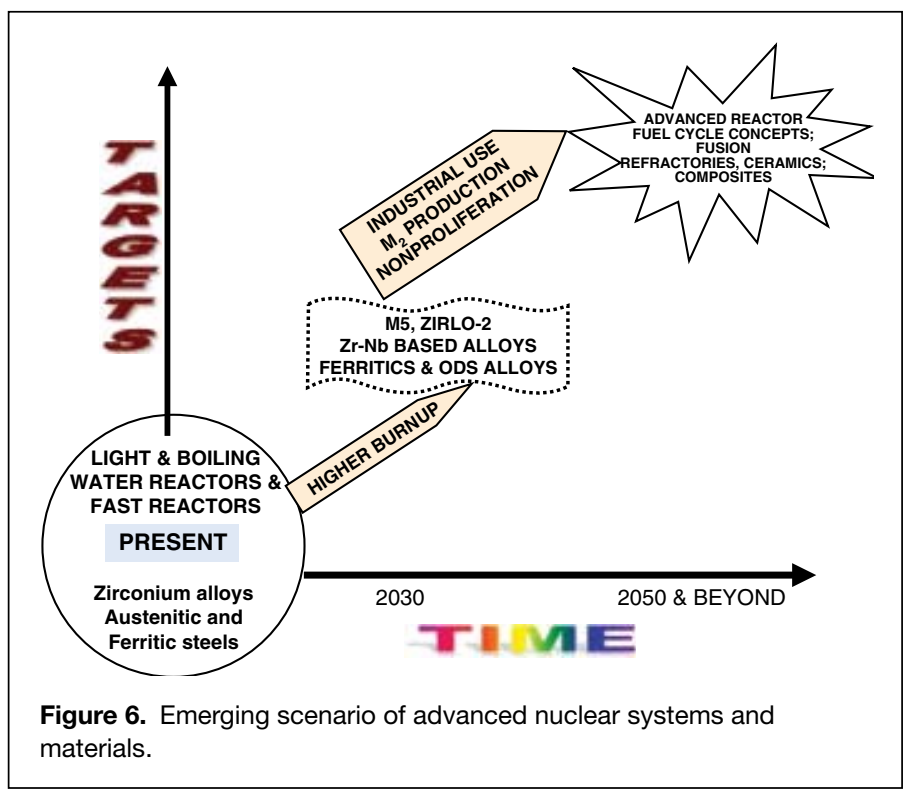


ated in the laboratory to service conditions should also be addressed. It is necessary to increase the confidence level of predictive models for describing the behavior of structural materials throughout the reactor lifetime of $60-100$ years. All of these efforts become crucial especially in the absence of test reactors with adequate capabilities for evaluation of in-reactor performance of materials. Despite all efforts, surprises in the in-reactor performance of materials are unavoidable, as a result of the synergy of different parameters, especially when improved performance targets and advanced technologies are being attempted.

There is a high level of confidence that these challenges can be met with the rich experience of the past, which has yielded new characterization techniques, processing capabilities, and modeling methods. The behavior of materials in different environments has been understood to a significant extent. Methodologies have been developed for lifetime prediction, manufacturing, and quality management. Online and in-service qualification of components and environment have been standardized. Multiscale modeling studies encompassing fundamental mechanisms of in-reactor performance are beginning to mature. One can now expect that the time taken for the development of newer materials such as ceramics and ceramic-metal matrix composites (from laboratoryscale development to commercial exploitation) should be significantly less than that of previous generations of nuclear materials.

\section{Summary}

Global nuclear energy production is predicted to grow by $21-44 \%$ by 2025 , mainly as a result of increased global energy demand, growing environmental concerns, increased capacity factors, and improved safety standards of nuclear reactors in the past few decades. The nuclear industry is focusing on long-term technological strategies to ensure multiple uses of nuclear power such as production of potable water and hydrogen and industrial heating. The major features of future nuclear technologies include nonproliferation, in situ incineration of longlived actinides and fission products, minimal generation of nuclear waste, cost competitiveness, and higher safety standards. Commercial power generation using fusion has a significant potential on a longer time horizon (second half of the $21 \mathrm{st}$ century). These ambitious targets demand commensurate developments in materials science and technology.

Nuclear materials researchers and technologists have gained rich experience in the behavior of present-generation materials, such as zirconium-based alloys and special steels, in the past three decades. The present trends suggest that these materials will undergo incremental changes in the immediate future, to increase the burnup of the fuel and the lifetime of the reactors. However, sustained R\&D on a wide spectrum of materials such as refractory alloys, composites, ceramics, low-activation steels, and coatings and the related processing technologies is essential to meet the demands of emerging nuclear technologies. Materials pose exciting challenges and opportunities to scientists and technologists to realize the ambitious objectives of the nuclear industry in the 21 st century.

\section{References}

1. International Atomic Energy Agency (TECDOC 1434, 24, 2004; www-pub. iaea.org/MTCD/publications/PDF/te_1434_web.pdf) (accessed January 2008).
2. World Association of Nuclear Operators, 2006 Performance Indicators (London, UK, 2006; http://wano.org.uk/Performancelndicators/PI_Trifold/ PI 2006_Trifold.pdf) (accessed January 2008).

3. International Atomic Energy Agency, "Nuclear Power and Sustainable Development," 13 (IAEA, Vienna, Austria, 2006; www.IAEA.org/Publications/ Booklets/NPSD0506.pdf) (accessed January 2008).

4. World Nuclear Association, Can Uranium Supplies Sustain the Global Nuclear Renaissance? (September 2005; www.world-nuclear.org/reference/ position_statements/uranium.html) (accessed January 2008).

5. OECD Nuclear Energy Agency and International Atomic Energy Agency, Uranium 2005-Resources, Production and Demand (OECD, Paris, France, 2005) p. 9.

6. Uranium Information Centre, Waste Management in the Nuclear Fuel Cycle (Australian Uranium Association, April 2007; www.uic.com.au/nip09.htm) (accessed January 2008).

7.www.iaea.org/worldatom/Programmes/Nuclear_Energy/NENP/NPTDS/Projects/ brochure.pdf (accessed January 2008).

8. http://nuclear.energy.gov/genIV/neGenIV1.html (accessed January 2008).

9. K.H. Handl, "Nuclear Heat Applications: Design Aspects and Operating Experience," 313 (IAEA-TECDOC-1056, 2004; www.iaea.org/OurWork/ST/ $\mathrm{NE} /$ inisnkm/nkm/aws/htgr/abstracts/abst_29067709.html) (accessed January 2008).

10. UIC Briefing Paper \#77 (September 2007; www.uic.com.au/nip77.htm) (accessed January 2008).

11. International Atomic Energy Agency, Thorium Fuel Utilization: Options and Trends (IAEA-TECDOC 1319, 2000).

12. B. Raj, Interim Report on Joint Study on Assessment Using the INPRO Methodology for an Innovative Nuclear Energy System based on a Closed Nuclear Fuel Cycle with Fast Reactors (CNFC-FR) (International Atomic Energy Agency, Vienna).

13. www.nea.fr/html/ndd/reports/2002/nea3109.html (accessed January 2008).

14. www.amdis.iaea.org/graphite (accessed January 2008).

15. www-nds.iaea.org/reports/nds-197.pdf (accessed January 2008).

16. www-nds.iaea.org/reports-new/indc-reports/indc-nds/indc-nds-0128.pdf (accessed January 2008).

17. G.R. Odette, G.E. Lucas, J. Met. 53 (7), 18 (2001).

18. V. Ganesan, J. Nucl. Mater. 256, 69 (1998).

19. www.astm.org/DIGITAL_LIBRARY/STP/PAGES/STP15182S.htm. (accessed January 2008).

20. www.pub.iaea.org/MTCD/Meetings/PDF plus/2005/SF_Presentations05/ Session2/Banerjee.pdf. (accessed January 2008).

21. K. Ehrlich, J. Konys, L. Heikinheimo, J. Nucl. Mater. 327 (2-3), 140 (2004).

22. M. Watteau, B. Estève, R. Guldner, R. Hoffman, Framatome ANP Extended Burnup Experience and Views on LWR Fuels (World Nuclear Association Annual Symposium, 2001; www.world-nuclear.org/sym/2001/watteau.htm) (accessed January 2008)

23. B. Raj, S.L. Mannan, P.R. Vasudeva Rao, M.D. Mathew, Sadhana 27 (5), 527 (2002).

24. C. Cawthorne, E.J. Fulton, Nature 216, 575 (1967); www.nature.com/ nature/journal/vz16/n5115/pdf/216575a0.pdf (accessed January 2008).

25. F. Garner, in Materials Science and Technology: A Comprehensive Treatment, R.W. Cahn, P. Haasen, E.J. Kramer, Eds.; B.R.T. Frost, Vol. Ed., 01.10A (VCH, 1994), p. 419.

26. R. Divakar, A. Banerjee, S. Raju, E. Mohandas, G. Panneerselvam, K. Siva Subramanian, M.P. Antony, 57th Annual Technical Meeting of the Indian Institute of Metals, Kolkata, India, November 2003.

27. J.L. Seren, V. Levy, P. Dubuisson, D. Gilbon, A. Mailard, A. Fissolo, H. Touron, R. Cauvin, A. Chalony, E. le Boulbin, in 15th International Symposium, ASTM STP1125, R.E. Stoller, A.S. Kumar, D.S. Gilles, Eds. (ASTM, West Conshohocken, $\mathrm{PA}, 1992)$

28. M.B. Toloczko, F.A. Garner, J. ASTM Int. 1, 4 (2004).

29. B. Raj, Int. J. Nucl. Energy Sci. Technol. 1 (2-3), 164 (2005).

30. B. Raj, U. Kamachi Mudali, Prog. Nucl. Energy 48, 283 (2006).

31. A.E. Ringwood, V.M. Oversby, S.E. Kesson, W. Sinclair, N. Ware, W. Hibbersson, A. Major, Nucl. Chem. Waste Manage. 2 (4), 287 (1981).

32. http://technology.newscientist.com/channel/tech/nuclear/mg13418263.000 (accessed January 2008).

33. D.D. Keiser, Jr., D.P. Abraham, W. Sinkler, J.W. Richardson, Jr., S.M. Mcdeavitt, J. Nucl. Mater. 279 (2-3), 234 (2000).

34. A. Almazouzi, E. Lucon, paper presented at EUROMAT-2005, Prague, Czech Republic; SCK7CEN, Mol., Belgium, 5-9 September, 2005.

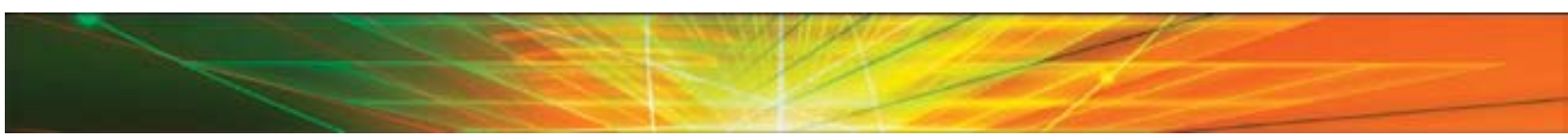




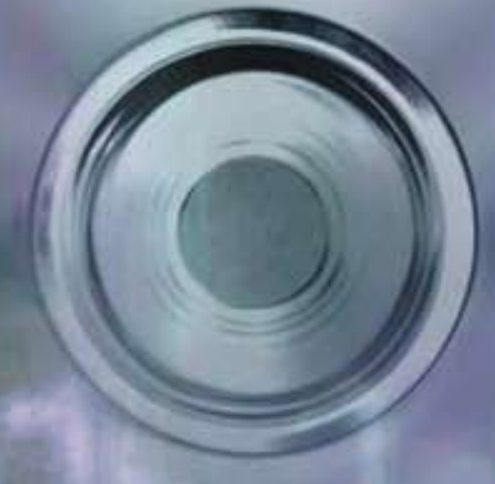

Foaturing

* Atomic parameters

\& Structural classifications

* Molecular visualization

Digitized pattern for every entry Customize instrumental parameters: radiation wavelengths $\&$ sources (X-ray, neutron or electron), instrumental optics, specimen conditions \& peak profiles

* Simulate crystallite sizes: thin film \& nanomaterials analyses

For more information: marketing@icdd.com www.icdd.com

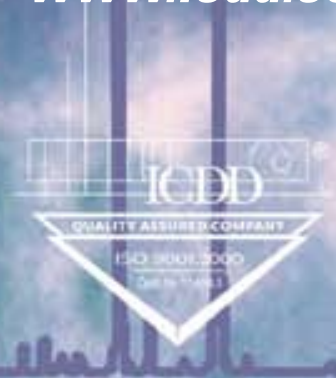

\section{IGantify 8 Quanitute}

Use the combined power of 4 databases to solve your phase identification problems!

* 272,232 Data sets with digital patterns

* 181,661 Data sets with $\mathrm{I} / \mathrm{I}_{\mathrm{c}}$

* 107,507 Data sets with atomic parameters

PDF-4+ combines the world's largest sources of inorganic materials data in a single, easily searched database. The comprehensive collection of inorganic bibliographic, diffraction, physical property, and crystal data is designed for problem solving and material identification. 